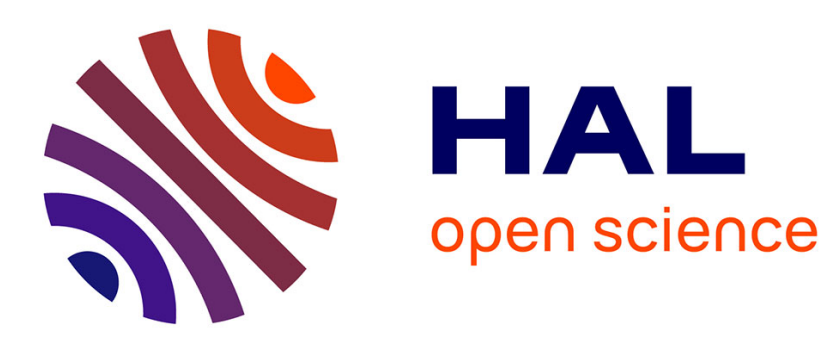

\title{
A Coaxial Probe Fixture Used For Extracting Complex permittivity Of thin Layers
}

Franck Moukanda Mbango, Fabien Ndagijimana, Jean Chilo, Pierre Saguet

\section{To cite this version:}

Franck Moukanda Mbango, Fabien Ndagijimana, Jean Chilo, Pierre Saguet. A Coaxial Probe Fixture Used For Extracting Complex permittivity Of thin Layers. WAMICON 2006, Dec 2006, ClearWater, United States. pp.Proceeding. hal-00194820

\section{HAL Id: hal-00194820 \\ https://hal.science/hal-00194820}

Submitted on 7 Dec 2007

HAL is a multi-disciplinary open access archive for the deposit and dissemination of scientific research documents, whether they are published or not. The documents may come from teaching and research institutions in France or abroad, or from public or private research centers.
L'archive ouverte pluridisciplinaire HAL, est destinée au dépôt et à la diffusion de documents scientifiques de niveau recherche, publiés ou non, émanant des établissements d'enseignement et de recherche français ou étrangers, des laboratoires publics ou privés. 


\title{
A Coaxial Probe Fixture Used for Extracting Complex Permittivity of Thin Layers
}

\author{
M. MOUKANDA, F. NDAGIJIMANA, J. CHILO and P. SAGUET \\ I.M.E.P-MINATEC, UMR 5130 CNRS/INPG/UJF, 3 Parvis Louis Néel, BP: 257, 38016 \\ Grenoble cedex 01 France, \\ Tél. : +33456529500, Fax : +33456529401 \\ moukanda@enserg.fr
}

\begin{abstract}
We have developed a broad-band technique for measuring the complex permittivity $\left(\varepsilon_{r}\right)$ of dielectric materials, especially thin layers. Our method is based on the use of a coaxial probe. The extraction of the complex permittivity uses a capacitance model valid in a broad frequency range dependent on the sample dimensions and the boundary conditions. Compared to transmission line method, one advantage of the coaxial probe is to avoid the costly lithography process, especially for Silicon or SOI substrates. To illustrate our technique, circular samples with a diameter of $2.922 \mathrm{~mm}$ are characterised in the range $0.5-25 \mathrm{GHz}$ for a thickness of $0.5 \mathrm{~mm}$ and various relative permittivity up to 12 with a fixed electric conductivity of $0.2 \mathrm{~S} / \mathrm{m}$.

Index Terms - Broad-band, Characterization and Dielectric Permittivity.

\section{Introduction}

The knowledge of dielectric properties is very important in studying the absorption of electromagnetic energy, and the propagation of signal in MMICs. Several techniques are found in the literature for determining the dielectric parameters [1]-[2]: cavity, transmission lines, open ended coaxial probes, MIM capacitance, free space [3], etc.

Cavities provide the most efficient permittivity characterization method when only a few frequencies are required [4]; so, suffer from disadvantage of being narrow-band [5]. Transmission line techniques are based on the use of lithography which is long and costly for some substrates like Silicon and SOI [6]. Based on measuring the scattering parameters of a discontinuity embedded in the transmission line, that technique is limited by the accuracy on relative permittivity and loss tangent in high frequency. This limitation is mainly due
\end{abstract}

to the resonance occurring at half-wavelength frequencies [7].

Open-ended coaxial probes are not suitable to thin film layers [8], because this method can give erroneous results if there is even a tiny air bubble or gap near its mouth [9]. MIM capacitance technique is limited in the deduction of losses [10]. Ellipsometry technique, based on free space, provide the permittivity characterization when only one frequency is needed [3].

In recent latest years, the coaxial probe has received attention and has gained favour of many researchers because of its simplicity and is therefore suitable for industrial use [9]-[12].

We develop a procedure to extract complex permittivity for thin dielectric layers, for a broad-band range of frequencies, without the use of the lithography. The sample is completely surrounded by a metallization unlike Stuchly works or Martens [9] . This technique is essentially based on measuring the reflection coefficient from a coaxial transmission line, terminated with the material under test as shown in figure 1 .

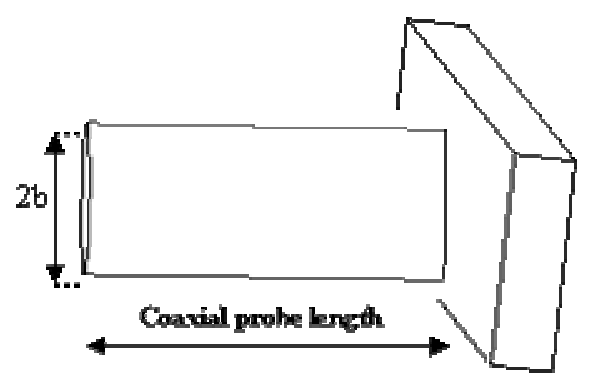

Figure 1a. Coaxial Probe Fixture 


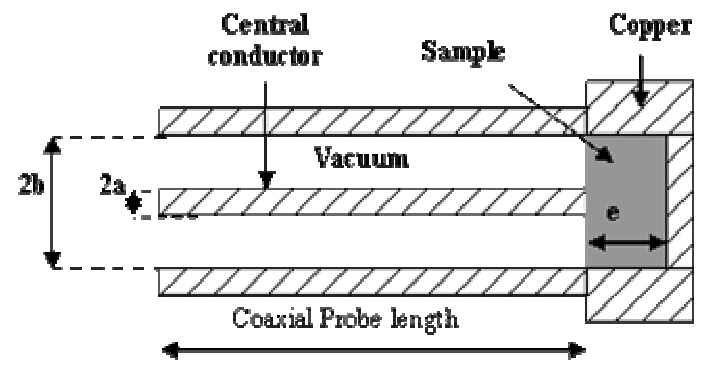

Figure 1b. Coaxial probe transverse section fixture

The method supposes that the material is not magnetic $\left(\mu_{\mathrm{eff}}=1\right)$.

Electromagnetic simulations were made with a 3D simulator based on the Finite Integration Method (FIM) in order to analyse the frequency limitations of the probe.

The main frequency limitation of the probe is due to the resonance depending on the dielectric permittivity and boundary conditions on different sides of the probe.

The electric equivalent model of this probe is showed in figure 2.

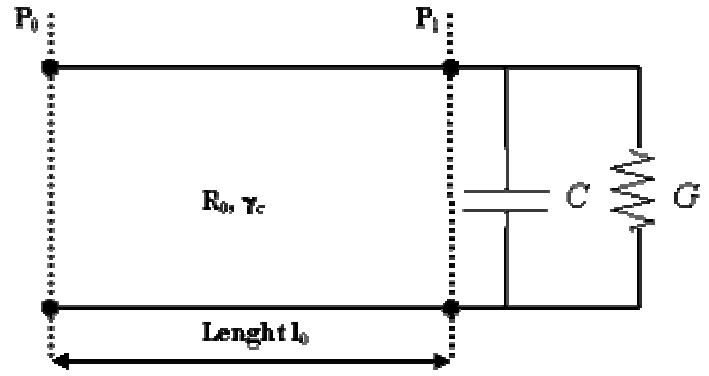

Figure 2. Equivalent Electric fixture

In this work, we give the theory of the method before digging deeper of the method through its principle secondly. Simulation results in order to consolidate the theory will be done in the third point before seeing thickness effects and ending by a conclusion.

\section{Principle of the method}

Consider a uniform waveguide ended by a capacitance composed of the sample to characterize. The reflection is measured in two cases: With and without the sample. From the measured reflection, we define the termination admittance [9] by the following relation:

$$
y_{\text {mat }}=\frac{1}{R_{0}} \frac{S_{11 C O}-S_{11 \text { mat }}}{S_{11 C O}+S_{11 \text { mat }}}
$$

where $R_{0}=50 \Omega, S_{11 \text { co }}$ the reflection coefficient measured from open-circuit and $S_{11 \text { mat }}$ the reflection coefficient measured with material.

Some hypotheses are made to simplify the extraction. We consider that the reflection coefficient is unity when we have the open circuit. The reference plan of the calibration is the plan $\mathrm{P}_{0}$ (fig.2).

\subsection{Capacitance model}

From the electrical circuit the admittances are expressed by:

$$
\left\{\begin{array}{c}
y_{\text {air }}=G_{\text {cond }}+j \omega C_{\text {air }} \\
y_{\text {mat }}=G_{\text {cond }}+G_{\text {mat }}+j \omega C_{\text {mat }}
\end{array}\right.
$$

Thereupon, effective permittivity is related to termination admittance by:

$$
\varepsilon_{\text {eff }}=\frac{y_{\text {mat }}-\operatorname{Re}\left(y_{\text {air }}\right)}{y_{\text {air }}-\operatorname{Re}\left(y_{\text {air }}\right)} \approx \frac{C_{\text {mat }}}{C_{\text {air }}}-j \frac{G_{\text {mat }}}{\omega C_{\text {air }}}
$$

From the effective permittivity depending on the dimensions of the probe, the intrinsic relative permittivity is calculated using a polynomial fitting function. The extraction of the conductivity requires an additional correction function depending on the frequency.

\subsection{Polynomial fitting function}

The parameters of this model are obtained from the electromagnetic simulations of different permittivity values, with and without losses.

We assume the complex dielectric permittivity linked to the effective permittivity by the following relation:

$$
\varepsilon_{r}^{*}=a \varepsilon_{e f f}^{*}+b
$$

where "a" and "b" are adjusted coefficients to minimize the fitting error.

The accuracy obtained on the relative permittivity depends on the metallic conductors, and leads also to a parasitic dependence with the frequency of the extracted conductivity.

Our investigations proved that best results are obtained when the sample is circular, and if it's totally surrounded by metallic walls. The choice of the connector to use is important in terms of frequency range 


\begin{tabular}{|c|c|c|}
\hline Connector & $\begin{array}{c}\text { SMA } \\
(\mathrm{D}=4.1 \mathrm{~mm})\end{array}$ & $\mathrm{K}(\mathrm{D}=2.922 \mathrm{~mm})$ \\
\hline $\begin{array}{c}\text { Fmax for } \\
\varepsilon_{\mathrm{r}}<12\end{array}$ & $\approx 14 \mathrm{GHz}$ & $\approx 23 \mathrm{GHz}$ \\
\hline \multicolumn{2}{|c|}{ Table 1. Frequency range as a function of } \\
connector dimensions
\end{tabular}

\subsection{Extraction Method Flow Chart}

We illustrate the global method in the following flow chart.

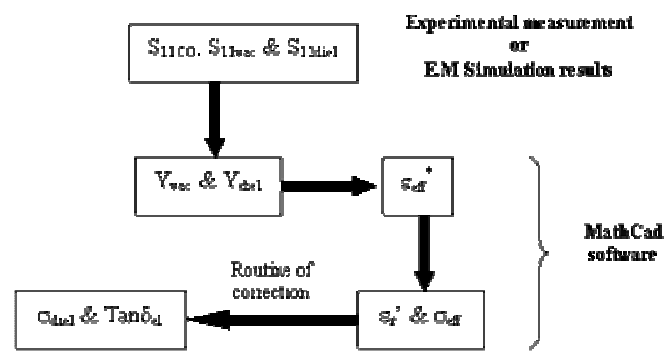

Figure 3. Diagram Flow Chart of the Method

The method is based on the use of measurements and Electromagnetic simulations.

In fact, metal conductivity appears in the final results because of the contact between the dielectric and the metallization (copper in our case).

\section{Simulation results}

Our purpose is to extract initial dielectric relative permittivity up to $25 \mathrm{GHz}$. We use a connector $\mathrm{K}$ $(2 \mathrm{a}=1.27 \mathrm{~mm}$ and $2 \mathrm{~b}=2.9 \mathrm{~mm})$ specified up to $40 \mathrm{GHz}$. The probe length is $1=10 \mathrm{~mm}$ with a diameter of $2.922 \mathrm{~mm}$. We consider different relative permittivity from 4 to 12 with a constant conductivity of $\sigma_{\text {diel }}=0.2 \mathrm{~S} / \mathrm{m}$ considered to be constant in broad-band.

The sample thickness is $\mathrm{e}=500 \mu \mathrm{m}$. The probe conductor (metal) is copper with conductivity of $\sigma_{\text {cop }}=58,13 \cdot 10^{6} \mathrm{~S} / \mathrm{m}$.

\subsection{Extraction of permittivity and electric conductivity}

These results show that the relative permittivity can be extracted with an error less than $2 \%$, from electromagnetic (E.M) simulations.

The operating frequency band is limited by the resonances of the cavity formed by the dielectric under test. The electric conductivity extracted when relative permittivity varies from 4 to 12 is shown in Figure $4 \mathrm{~b}$.

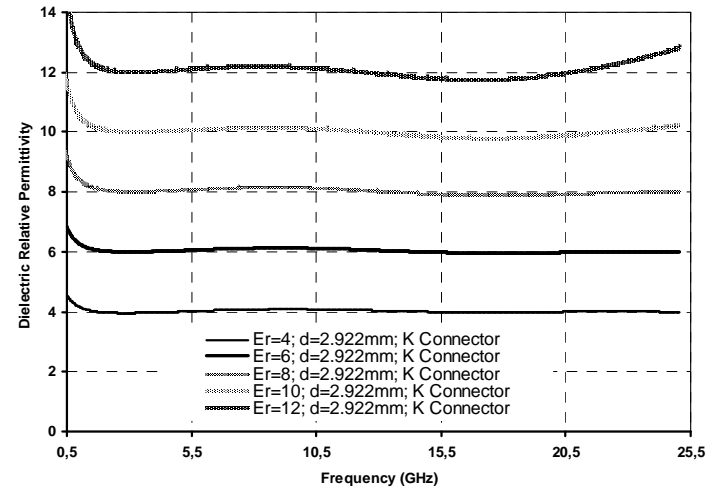

Figure 4a. Dielectric Relative Permittivity with losses $\sigma=0.2 \mathrm{~S} / \mathrm{m}$

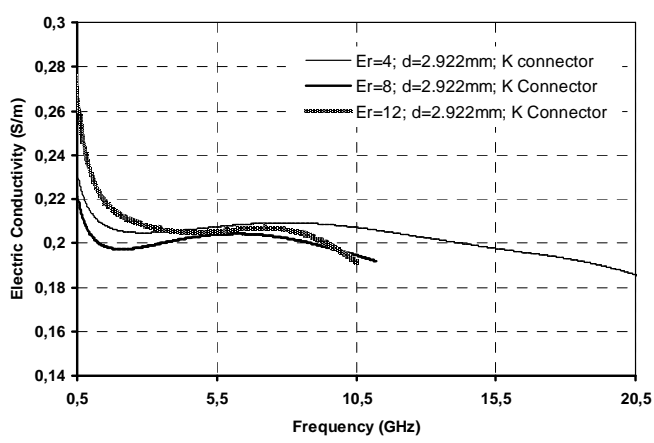

Figure 4b. Electric Conductivity (S/m) Extracted from E.M.S before corrected the conductivity of the sample.

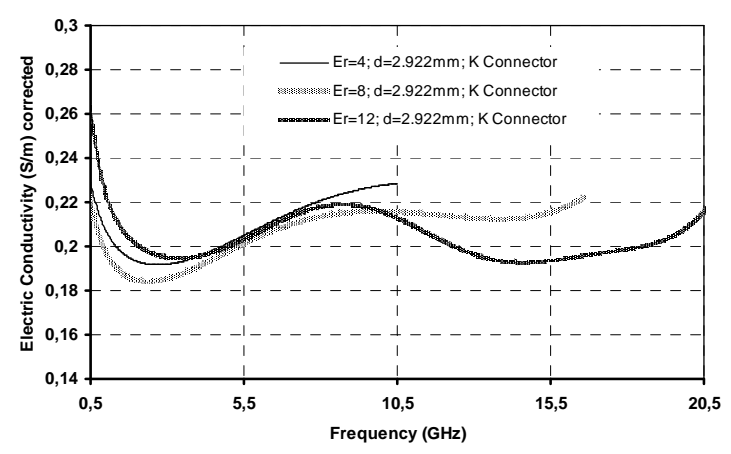

Figure 4c. Electric Conductivity (S/m) Extracted from E.M.S after corrections of conductors losses

We observe some variations of the extracted conductivity according to the permittivity. So, we develop another principle of correction through MATHCAD to get high in frequency. We developed a routine to make that correction. Here are results we obtain. 
These results show that depending on the value of the relative permittivity, the extraction of electric conductivity is limited in frequency.

\subsection{Extraction of variable electric conductivity}

Now, we change the sample conductivity when the relative permittivity is $\varepsilon_{\mathrm{r}}=12$ and its diameter is $\mathrm{d}=2.922 \mathrm{~mm}$, using the connector $\mathrm{K}$. We set up the following conductivities: $\sigma_{\text {diel }}=0.2 ; 0.5$ and $1 \mathrm{~S} / \mathrm{m}$ (Figure 5).

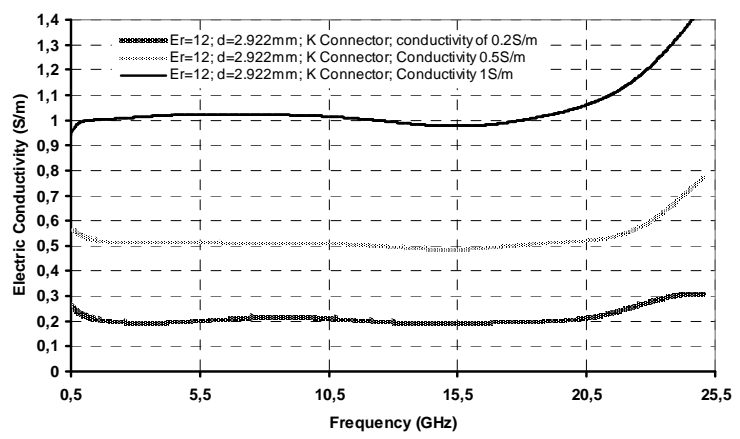

Figure 5. Electric Conductivity (S/m) Extracted from E.M.S with different conductivity values.

These results are in agreement with electromagnetic simulations (E.M.S). The method used proves that conductivity doesn't influence the principle adopted up.

Using this fixture, we can notice also if you can't make correction on the conductivity, you will just extract easily that up around $10 \mathrm{GHz}$. But if you do this, the frequency bandwidth will grow up to $20.5 \mathrm{GHz}$.

\section{Conclusion}

In this paper we have discussed a new coaxial probe technique for accurate extraction of the relative permittivity of thin film. We demonstrated that approach can be readily applied with good precision to layers having thickness greater than $400 \mu \mathrm{m}$.

The frequency range depends on dielectric dimensions. The probe with circular sample and metallic walls operates up to $25 \mathrm{GHz}$ for relative permittivity up to 10 . We observe some undulations coming from the driving line mismatch, but this affects the accuracy on of the permittivity extraction

In low frequencies, some problems of mesh refinement from the electromagnetic simulator affect the accuracy. The sample diameter must be chosen equal to the outside conductor of the connector to optimise the frequency range of the characterisation.

The sample thickness associated to the value of the relative permittivity determines the capacitance to be extracted.
This method has been applied to circular samples with a diameter of $2.922 \mathrm{~mm}$, a thickness of $0.5 \mathrm{~mm}$, characterised in the range $0.5-25 \mathrm{GHz}$ for relative permittivity up to 12 with an electric conductivity of $0.2 \mathrm{~S} / \mathrm{m}$.

\section{REFERENCES}

[1] M. Sucher and J. Fox, "Handbook of Microwave Measurements," $3^{\text {rd }}$ ed. New York: Wiley, 1963.

[2] M. N. Afsar, H. Ding, \& K. Tourshan, "A New $60 \mathrm{GHz}$ Open-Resonator Technique for Precision Permittivity and Loss-tangent Measurement”, IEEE Trans. On Instrumentation \& Measurement, vol. 48, pp. 626-630, April 1999.

[3] F. Sagnard, F. Bentabet and C. Vignat, "Ain Situ Measurements of the Complex Permittivity of Materials Using Reflection Ellipsometry in the Microwave Band: Experiments (Part I)", IEEE Trans. On Instrumentation \& Measurement, vol. 54, no. 3, pp. 1266-1273, June 2005.

[4] R. G. Carter, "Accuracy of Microwave Cavity Perturbation Measurements", IEEE Trans. On Microwave Theory \& Techniques, vol. 49, pp. 918-923, May 2001.

[5] R. Birnbaum and J. Franeau, "Measurement of the Dielectric Constant and Loss of Solids and Liquids by a Cavity Perturbation Method," J. Appl. Phys., vol. 20, pp. 817-818, 1949.

[6] Michael D. Janezic, Jeffrey A. Jargon,, "Complex Permittivity Determination from Propagation Constant Measurements", IEEE Microwave and Guided Wave letters, Vol.9, $\mathrm{N}^{\circ} .2$, pp. 76-78, February 1999.

[7] Jawad Abdulnour, Cevdet Akyel and Ke Wu, "A Generic Approach for permittivity Measurement of Dielectric materials Using a Discontinuity in a rectangular Waveguide or microstrip Line," IEEE Transactions on Microwave Theory and Techniques, Vol.43, $\mathrm{N}^{\circ} .5$, pp. 1060-1066, May 1995.

[8] Devendra Misra, " On the Measurement of the Complex Permittivity of Materials by an Open-Ended Coaxial Probe”, IEEE Microwave \& Guided Wave Letters., vol. 5, no. 5, pp. 192-198, May 1995.

[9] H. C. F. Martens, J. A. Reedijk and H. B. Brom, "Measurement of the Complex Dielectric Constant down to Helium Temperatures. I. Reflection Method from $1 \mathrm{MHz}$ to $20 \mathrm{GHz}$ Using an Open-Ended Coaxial Line," Review of Scientific Instruments, vol. 71, no. 2, pp. 473477, February 2000.

[10] M. Gallitre. J-D. Arnould, P. Benech, O. Exshaw, M. Thomas, A. Farcy \& J. Torres, "Caractérisation Electrique de l'isolant Inter-Armature de Capacités $\mathrm{Cu}$ $\mathrm{Si}_{3} \mathrm{~N}_{4}-\mathrm{Cu}$ entre $45 \mathrm{MHz}$ et $40 \mathrm{GHz}$ en Technologie CMOS $120 \mathrm{~nm}$, , JCMM, E4, mars 2006.

[11] A. Raj, W. S. Holmes, "Wide Bandwidth measurement of Complex Permittivity of Liquids Using Coplanar Lines," IEEE Trans. On instrumentation.., vol. 50, no. 4, pp. 905908, August 2001.

[12]S. S. Stuchly, C. L. Sibbald and J. M. Anderson, “A new Aperture Admittance Model for Open-Ended Waveguides”, IEEE Trans. Microwave Theory \& Tech. vol. 42, no. 2, pp. 192-198, February 1994. 